\title{
Genetic mutations in SPINK1, CFTR, CTRC genes in acute pancreatitis
}

Dorota Koziel ${ }^{1 *}$, Stanislaw Gluszek ${ }^{1,2}$, Artur Kowalik ${ }^{3}$, Malgorzata Chlopek ${ }^{3}$ and Liliana Pieciak ${ }^{3}$

\begin{abstract}
Background: Explanation of the ultimate causes of acute and chronic pancreatitis is challenging. Hence, it is necessary to seek various etiological factors, including genetic mutations that may be of importance in triggering recurrence and progression of acute to chronic pancreatitis. The aim of this study was to determine the frequency of genetic mutations in patients with acute pancreatitis and to investigate their relationship with the etiology and clinical course.

Methods: The study included 221 patients treated for acute pancreatitis and 345 healthy subjects as a control group. Peripheral blood samples were collected from each study participant and genomic DNA was isolated. Genotyping of common mutations in the SPINK1 (p.N34S and p.P55S) and CTRC (p.I259V, p.V235I, p.K247_R254del, p.E225A) genes was performed using the high-resolution melting method. Mutations in the CFTR p.F508del (delF508_CTT) were genotyped using allele-specific amplification polymerase chain reaction. All detected mutations were confirmed with direct capillary DNA sequencing.

Results: Mutations in SPINK 1, CFTR and CTRC were detected in $6.3 \%, 2.3 \%$ and $1.8 \%$ of patients with acute pancreatitis versus $3.2 \%, 3.8 \%$ and $1.2 \%$ of volunteers in the control group. No relationship was found between the detected mutations and severity of acute pancreatitis: mild acute pancreatitis, mutation of CFTR in 4 (2.8 \%) and CTRC in 2 (1.4\%) patients; severe acute pancreatitis, mutation of CFTR and CTRC in 1 (2.6\%) case each. The SPINK1 mutation was significantly more frequent in $8(10.4 \%)$ severe cases than in $6(4.2 \%)$ mild cases $(P<0.05)$, and was observed in 5/70 (7.1\%) patients with alcohol-related AP, 5/81 (6.2 \%) with biliary AP, and 4/63 (6.3 \%) in those without any established cause of the disease.
\end{abstract}

Conclusions: Mutation p.N34S in SPINK1 may predispose patients to acute pancreatitis, especially in those abusing alcohol, and may promote a more severe course of the disease.

Keywords: Acute pancreatitis, Etiology, SPINK1 mutations, CFTR mutations, CTRC mutations

\section{Background}

The most frequent causes of acute pancreatitis (AP) are gallstones and alcohol [1]. However, in a considerable number of individuals, even many attacks of gallstones and multiple episodes of alcohol abuse do not lead to acute pancreatitis $[2,3]$. It was presumed that repeated acute pancreatitis and chronic pancreatitis, especially with a family history of pancreatic disease, may have a genetic background. It is considered that genetic etiology is responsible for $\sim 25 \%$ of all cases of chronic pancreatitis;

\footnotetext{
* Correspondence: dorota.koziel@wp.pl

${ }^{1}$ Faculty of Health Sciences, Jan Kochanowski University, Kielce, Poland Full list of author information is available at the end of the article
}

however, it should be emphasized that $40 \%$ of cases are considered to be idiopathic [4].

Epidemiological investigations have confirmed high morbidity due to acute pancreatitis among adult inhabitants of the Kielce Region in Poland [5]. In 2011, pancreatic events occurred for the first time in $79.7 / 100,000$ inhabitants. In many patients, idiopathic pancreatitis was diagnosed. The study showed that the taking of family and environmental history, which could explain the causes of the disease in some cases, was frequently omitted in the analysis of etiology [5]. This inclined us to explore further the collected epidemiological data.

In the pathogenesis of pancreatitis, various groups of genetic mutations may play an important role. Mutations 
in the cationic trypsinogen (PRSS1), anionic trypsinogen (PRSS2), pancreatic secretory trypsin inhibitor (SPINK1), cystic fibrosis transmembrane conductance regulator $(C F T R)$, chymotrypsinogen $(C T R C)$, calcium-sensing receptor $(C A S R)$ and the protein claudin-2 (CLDN2) genes were found in different types of pancreatitis [6-9]. The first described was a mutation of the trypsinogen gene in exon 3 (p.R122H). In other studies, other mutations in this gene were also analyzed, and related with hereditary pancreatitis, such as p.N291, p.A16V, p.R122C and p.D22G [10, 11].

The majority of studies have focused on determining the importance of various mutations in the etiology of pancreatitis. In the case of confirmed presence of a mutation, the course of acute episodes of pancreatitis is rarely investigated in the context of various environmental factors and other factors known as determinants of acute pancreatitis.

The results of studies of mutations and their contribution to the etiology of acute and chronic pancreatitis are divergent; therefore, it seems justifiable to analyze further patients with acute pancreatitis, which is a lifethreatening event, and remains an important clinical challenge.

The aim of this study was to determine the frequency of genetic mutations in SPINK1, CFTR and CTRC genes in patients with acute pancreatitis (AP), as well as to investigate their relation with the etiology and clinical course.

\section{Methods}

The study included 221 patients with acute pancreatitis, inhabitants of the Kielce Region in Poland, who gave their informed consent for collecting genetic material. Diagnosis of mild, moderate or severe acute pancreatitis (SAP), according to the Atlanta 2012 classification, was the criterion for inclusion in the study. Diagnosis of AP was based on the joint interpretation of medical history, physical examination and targeted laboratory tests. The diagnosis was based upon satisfaction of at least 2 of the following 3 criteria: (1) upper abdominal pain of sudden onset, frequently radiating towards the back; (2) lipase or amylase activity in serum $>3$ times the upper limit of normal; and (3) results of imaging tests that allow one to obtain cross-sectional images: computed tomography (CT), nuclear magnetic resonance (NMR), or ultrasonography (USG). In the analysis of the etiology of AP, medical history taking can determine alcohol consumption, occurrence of concomitant diseases, drug intake, procedures performed, and endoscopic retrograde cholangiopancreatography (ERCP). Biliary etiology was confirmed based on USG, CT, NMR, and/or ERCP, only if there were indications for performance of these procedures, for example, icterus or triple elevation of alanine aminotransferase level. Endoscopic ultrasonography was performed in some patients to confirm biliary AP. Alcohol consumption was evaluated with the Short Alcohol Dependence Data (SADD) Questionnaire, and selfestimated alcohol consumption via interview. Acute pancreatitis was diagnosed if a patient gained $\geq 10$ points on the SADD Questionnaire, or if a period of alcohol abuse lasted $\geq 1$ year, and the daily dose was $40 \mathrm{~g}$ of pure ethanol.

Diagnosis of chronic pancreatitis was an exclusion criterion. The control group included adult volunteers selected by random sampling, without any apparent concomitant diseases that could have affected the structure and expression of genes to be tested in the study.

The control group consisted of 345 healthy inhabitants of the Kielce Region: 223 women and 122 men; mean age 45.1 (44 in women, 47 in men) years, in a general good state of health, with body mass index 18.5-30. The study group included 221 patients who had acute pancreatitis (88 female, 133 male); mean age 55.4 (56.2 in women, 51.4 in men). The course of AP was mild in $65.2 \%$ of patients, moderately severe in $17.6 \%$, and severe in $17.2 \%$. The percentage of women in the study group was significantly lower compared with the control group, while the mean age was significantly higher in the study than control group.

The study was approved by the Committee on Bioethics at the Faculty of Health Sciences, Jan Kochanowski University in Kielce. Each patient and member of the control group gave their informed consent to perform the genetic testing.

\section{DNA isolation}

Peripheral blood samples were drawn from all study participants and collected in EDTA tubes. DNA was isolated using Micro AX Blood Gravity Kit (A\&A Biotechnology, Gdańsk, Poland).

Quality and concentration of isolated DNA was measured by Nano Drop 2000 (Thermo Scientific, TK Biotech, Poland).

Genotyping was performed using the following molecular biology techniques: allele-specific PCR (ASAPCR) and high-resolution melting (HRM)-PCR, and all detected mutations were confirmed by direct capillary sequencing. To validate ASA-PCR and HRM-PCR, the first 164 samples were sequenced in parallel, irrespective of genotyping results.

\section{Mutation detection in CFTR gene}

The p.F508del (delF508_CTT) mutation was detected using $10 \mu \mathrm{l}$ ASA-PCR mixture containing $5 \mu \mathrm{lSybr}$ Green Kit (Qiagen, Syngen-Biotech, Wrocław, Poland), $1 \mu \mathrm{l}$ water, $1 \mu \mathrm{l}$ each primer, and $1 \mu \mathrm{l}$ DNA template. 
PCR was performed in a Veriti 96 Well Thermal Cycler (Applied Biosystems, USA). The cycling profile was set at $95{ }^{\circ} \mathrm{C}$ initial denaturation for $1 \mathrm{~min}$, followed by 35 cycles of $15 \mathrm{~s}$ at $95{ }^{\circ} \mathrm{C}, 15 \mathrm{~s}$ at $60{ }^{\circ} \mathrm{C}, 30 \mathrm{~s}$ at $72{ }^{\circ} \mathrm{C}$, and a final extension at $72{ }^{\circ} \mathrm{C}$ for $7 \mathrm{~min}$. ASA-PCR product detection and visualization were performed using a microchip electrophoresis system MCE-202 Multi NA (Shimadzu, Shim-pol, Warsaw, Poland).

\section{Mutation detection in SPINK1 and CTRC genes}

Mutation detection was performed using primers (Table 1) flanking genetic regions containing the following mutations in: SPINK1 exon 3 (p.N34S and p.P55S), and CTRC exon 3 and 7 (p.I259V, p.V235I, p.K247_R254del, and p.E225A).

HRM-PCR mixture was composed of $5 \mu$ Type-it HRM PCR Kit (Qiagen, Synge-Biotech), $7 \mu \mathrm{l}$ water, $1 \mu \mathrm{l}$ each forward and reverse primer (Table 1), and $1 \mu \mathrm{l}$ template DNA. PCR was performed by using Rotor Gene (Qiagen, Syngen-Biotech). Cycling conditions were: 5 min initial denaturation at $95^{\circ} \mathrm{C}$, followed by 40 cycles of $10 \mathrm{~s}$ at $95{ }^{\circ} \mathrm{C}, 30 \mathrm{~s}$ at $65^{\circ} \mathrm{C}, 30 \mathrm{~s}$ at $65{ }^{\circ} \mathrm{C}$, but during the first 10 cycles, we used a touchdown mode of $1{ }^{\circ} \mathrm{C}$ per cycle, $10 \mathrm{~s}$ at $72{ }^{\circ} \mathrm{C}$, and a heteroduplex formation consisting of $10 \mathrm{~s}$ at $95{ }^{\circ} \mathrm{C}$ and $20 \mathrm{~s}$ at $40{ }^{\circ} \mathrm{C}$. Melting temperature range was $75-80{ }^{\circ} \mathrm{C}$ for exon 3 SPINK1, and $75-95^{\circ} \mathrm{C}$ for exon 7 CTRC. For CTRC exon 3, there were 37 cycles with touchdown $\left(1{ }^{\circ} \mathrm{C} /\right.$ cycle $)$ and a melting range of $80-93{ }^{\circ} \mathrm{C}$.

Polymorphisms and mutations in the HRM-PCR products were detected based on a change in the shape of a PCR product melting curve. All detected polymorphisms and mutations were then confirmed by capillary sequencing.

For capillary sequencing, the primers used - HRM-PCR products (Table 1 ) - were enzymatically purified using Exo SAP reagent containing phosphatase and exonuclease. The purified PCR product was sequenced with BigDye Terminator v3.1 Cycle Sequencing Kit (Applied Biosystems). The reaction conditions were 25 cycles of
$96{ }^{\circ} \mathrm{C}$ for $10 \mathrm{~s}, 55^{\circ} \mathrm{C}$ for $5 \mathrm{~s}$, and $60^{\circ} \mathrm{C}$ for $105 \mathrm{~s}$ ). The reaction products were purified after sequencing by using Big Dye X Terminator Kit (Applied Biosystems). Sequencing was carried out on a 3130 Genetic Analyzer (Applied Biosystems). The resulting chromatograms were analyzed manually and compared using BLAST software from the NCBI site (Table 1).

\section{Statistical analysis}

Differences between the 2 groups were analyzed by examining the proportions of patients in each group representing a particular category (e.g., occurrence of SPINK1 mutation), using the 1-tailed $\mathrm{Z}$ test for comparing 2 proportions.

The relationships between gender and occurrence of SPINK1, CFTR or CTRC mutations in patients with AP and in the control group were analyzed using a more conservative test. The data sets were displayed in the form of $2 \times 2$ contingency tables with gender as the row variable, and occurrence of mutation as the column variable. Some cell numbers were small and there were big differences between cell numbers. The null hypothesis that the specific mutation occurred equally in men and women was verified with Fisher's exact test. Odds ratios wereto compare the odds of occurrence of a specific event in the study group versus the control group, and $95 \%$ confidence intervals were also reported.

\section{Results}

There were no significant differences in frequencies of SPINK1, CFTR and CTRC mutations when comparing the male and female patients. The data sets were displayed in the form of $2 \times 2$ contingency tables with gender as the row variable and occurrence of mutations as the column variable. Some cell numbers were small and large differences occurred between cell numbers. In such a case, Fisher's exact test was applied to analyze the relationships between the variables. The null hypothesis was that the specific mutation occurred equally in men and women (Table 2).

Table 1 Sequences of primers used for the reaction and methods used

\begin{tabular}{lll}
\hline Gene & Method & Primer sequence \\
\hline CFTR ex10 & allele-specific PCR & GCAAGTGAATCCTGAGCGTG \\
& & TGGGTAGTGTGAAGGGTTCAT \\
SPINK1 ex3 & GCACCATTAAAGAAATATCATTGG \\
& HRM/capillary sequencing & TTGCTATGAACTCAAGAATGGAGA \\
CTRC ex7 & F R capillary sequencing & CCGATTTCAAAACATAACACTG \\
& HRM/capillary sequencing & CTATGCCCTCCCGGTCTGG \\
CTRC ex3 & GGACAGCTGTGGAGGCAG \\
& & CTGACACACAGCCCTCCC \\
\hline
\end{tabular}


Table 2 Contingency Table for analysis of the association between gender and mutation in SPINK1, CFTR, CTRC in the group of patients with AP and the control group of healthy individuals without a past history of acute pancreatitis

\begin{tabular}{|c|c|c|c|c|c|c|c|c|c|}
\hline & \multicolumn{3}{|c|}{ SPINK 1} & \multicolumn{3}{|c|}{ CFTR } & \multicolumn{3}{|c|}{ CTRC } \\
\hline & Yes & No & $p$-value & Yes & No & $p$-value & Yes & No & $p$-value \\
\hline \multicolumn{10}{|l|}{ Patients with AP } \\
\hline Female & 5 & 83 & $\mathrm{NS}^{*}$ & 4 & 84 & NS & 1 & 87 & NS \\
\hline Male & 9 & 124 & & 1 & 132 & & 3 & 130 & \\
\hline Marginal Column Totals & 14 & 207 & - & 5 & 216 & - & 4 & 217 & - \\
\hline \multicolumn{10}{|c|}{ Control group of healthy individuals } \\
\hline Female & 8 & 215 & NS & 6 & 217 & NS & 2 & 221 & NS \\
\hline Male & 3 & 119 & & 7 & 115 & & 2 & 120 & \\
\hline Marginal Column Totals & 11 & 334 & - & 13 & 332 & & 4 & 341 & - \\
\hline
\end{tabular}

$\mathrm{NS}^{*}$ no statistical significance

In patients with AP, the gene mutations detected compared with the controls were as follows: SPINK1, $6.3 \%$ patients versus $3.2 \%$ controls; CFTR, $2.3 \%$ patients versus $3.8 \%$ controls; and CTRC, $1.8 \%$ patients versus $1.2 \%$ controls (Table 3 ).

HRM-PCR and direct sequencing detected 12 p.N32S and 2 p.P55S mis-sense mutations in SPINK in patients, which together constituted $6.3 \%$ of AP cases. However, using ASA-PCR, p.F508del mutations were found in 5 (2.3\%) AP cases. HRM-PCR and direct sequencing detected $4(1.8 \%)$ mutations in CTRC. All detected mutations were of the mis-sense type, that is, 2 p.V235I, 1 p.I259V and 1 p.K247_R254del (Table 4).

In 1 patient with recurrence of moderately severe AP with alcohol etiology, we observed p.N34S mutation in SPINK1 and p.V235I mutation in CTRC.

\section{SPINK1}

The SPINK1 mutation was more common in the AP than the control group. The observed proportions were 0.063 and 0.032 , respectively. The $\mathrm{Z}$ score was 1.777 , and the corresponding $P$ value was 0.03 . The patients with mild AP had a significantly lower proportion of mutations in SPINK1 than those with moderately severe or severe AP. The observed proportions were 0.042 and 0.104 , respectively. The $\mathrm{Z}$ score was 1.8095 and the $P$ value was 0.03 .

In considering the causes of AP (alcoholic, biliary and idiopathic), no differences were found in the frequency of mutation in SPINK1. No significant differences were observed between the frequency of mutations in SPINK1 in the subgroups with and without recurrence.

The study group without recurrent AP had a higher proportion of mutation in SPINK1 than the control group had, and the difference was almost significant at the 0.05 level. The observed proportions were: 0.065 and 0.032 , respectively. The $\mathrm{Z}$ score was 1.6436 and the $P$ value was 0.0505 (Table 5).

\section{CFTR}

There was no significant difference in the frequency of mutation in CFTR in the AP and control groups. The observed proportions were: 0.023 and 0.038 , respectively. The $\mathrm{Z}$ score was -0.9959 and the $P$ value was 0.15 (Table 5).

Table 3 Clinical course of AP according to causes of the disease in the group of patients with mutation diagnosed

\begin{tabular}{|c|c|c|c|c|c|}
\hline & Alcohol & Gallstones & Cancer & Idiopathic & Control population \\
\hline & $N=70(31.7 \%)$ & $N=81(36.7 \%)$ & $N=7(3.2 \%)$ & $N=63(28.5 \%)$ & $N=345$ \\
\hline SPINK1 $n=14(6.3 \%)$ & & & & & $11(3.2 \%)$ \\
\hline Mild AP & $2(2.9 \%)$ & $2(2.5 \%)$ & 0 & $2(3.2 \%)$ & \\
\hline Moderate and severe AP & $3(4.3 \%)$ & $3(3.7 \%)$ & 0 & $2(3.2 \%)$ & \\
\hline CFTR $n=5(2.3 \%)$ & & & & & $13(3.8 \%)$ \\
\hline Mild AP & $1(1.4 \%)$ & $2(2.5 \%)$ & $1(14.3 \%)$ & 0 & \\
\hline Moderate and severe AP & & $1(1.2 \%)$ & 0 & 0 & \\
\hline CTRC $n=4(1.8 \%)$ & & & & & $4(1.2 \%)$ \\
\hline Mild AP & $1(1.4 \%)$ & $1(1.2 \%)$ & 0 & 0 & \\
\hline Moderate and severe AP & $1(1.4 \%)$ & $1(1.2 \%)$ & 0 & 0 & \\
\hline
\end{tabular}


Table 4 Mutations detected in the SPINK 1, CFTR, CTRC genes in correlation with clinical data

\begin{tabular}{|c|c|c|c|c|c|c|c|}
\hline Gene mutation & $\begin{array}{l}\text { No. of } \\
\text { patients }\end{array}$ & BMI & $\begin{array}{l}\text { Alcohol abuse } \\
\text { ( } \geq 40 \text { g daily) }\end{array}$ & $\begin{array}{l}\text { Cigarette smoking } \\
\text { (currently) }\end{array}$ & $\begin{array}{l}\text { Pancreatic diseases } \\
\text { in family }\end{array}$ & Concomitant diseases & Recurrences \\
\hline $\begin{array}{l}\text { SPINK1 p.N34S } \\
\text { c.101A > G exon } 3\end{array}$ & $\begin{array}{l}12 \\
(5.42 \%)\end{array}$ & & & & & & \\
\hline 1 & & 26.0 & Yes & No & No & None & Yes \\
\hline 2 & & 20.2 & Yes & No & No & None & No \\
\hline 3 & & 29.8 & No & No & & None & No \\
\hline 4 & & 24.0 & No & No & No & $\begin{array}{l}\text { cardiovascular diseases, } \\
\text { atherosclerosis, } \\
\text { Parkinson's disease }\end{array}$ & No \\
\hline 5 & & 29.4 & No & No & No & None & No \\
\hline 6 & & 23.4 & Yes & Yes & No & None & Yes \\
\hline 7 & & 22.4 & Yes & Yes & No & $\begin{array}{l}\text { gallstones, } \\
\text { gastroesophageal } \\
\text { reflux disease, } \\
\text { psychoorganic } \\
\text { syndrome }\end{array}$ & No \\
\hline 8 & & 27.7 & No & No & No & None & No \\
\hline 9 & & 26.4 & No & Yes & Yes & arterial hypertension & Yes \\
\hline 10 & & 25.4 & No & No & No & None & Yes \\
\hline 11 & & 30.1 & Yes & Yes & No & $\begin{array}{l}\text { arterial hypertension, } \\
\text { type-2 diabetes }\end{array}$ & No \\
\hline 12 & & 26.6 & Yes & No & No & None & No \\
\hline SPINK1 p.P55S c.163C> & 2 (0.9\%) & & & & & & \\
\hline 1 & & 27.0 & Yes & No & No & None & \\
\hline 2 & & 19.0 & No & No & No & $\begin{array}{l}\text { cardiovascular diseases, } \\
\text { gallstones }\end{array}$ & No \\
\hline $\begin{array}{l}\text { CFTRp.F508del (delF508) } \\
\text { c.1521_1523 delCTT } \\
\text { C>T exon } 3\end{array}$ & $5(2.3 \%)$ & & & & & & \\
\hline 1 & & 20.2 & No & No & Yes & cardiovascular diseases & No \\
\hline 2 & & 26.4 & No & No & No & arterial hypertension & Yes \\
\hline 3 & & 25.6 & No & No & No & arterial hypertension & No \\
\hline 4 & & 19.2 & No & No & No & pancreatic cancer & No \\
\hline 5 & & 26.0 & Yes & Yes & No & None & No \\
\hline $\begin{array}{l}\text { CTRC p.V2351 } \\
\text { c.703G > A exon } 7\end{array}$ & $2(0.9 \%)$ & & & & & & \\
\hline 1 & & 23.4 & Yes & Yes & No & None & No \\
\hline 2 & & 22.9 & Yes & Yes & No & None & Yes \\
\hline $\begin{array}{l}\text { p.1259V c.775A >C } \\
\text { exon } 7\end{array}$ & $1(0.5 \%)$ & & & & & & \\
\hline 1 & & 27.0 & No & No & Yes & & Yes \\
\hline $\begin{array}{l}\text { p.K247_R254 } \\
\text { delc.738_761del24 exon } 7\end{array}$ & $1(0.5 \%)$ & & & & & & \\
\hline 1 & & 26.2 & No & No & No & None & No \\
\hline
\end{tabular}

\section{CTRC}

There was no significant difference in the frequency of mutation in CTRC in the AP and control groups. The observed proportions were: 0.018 and 0.012 , respectively. The $\mathrm{Z}$ score was 0.6396 and the $P$ value was 0.26 (Table 5).

\section{Discussion}

SPINK1 is a specific trypsin inhibitor and an acute phase protein that is secreted by the acinar cells. SPINK1 protein plays a role in the prevention of premature activation of zymogen that is catalyzed by trypsin within the pancreatic duct system or the acinar tissue. A reactive 
Table 5 Frequency and odds ratios (95\% Cl) of mutations in SPINK1, CFTR, CTRC in the individual groups with acute pancreatitis and in the control group

\begin{tabular}{|c|c|c|c|c|c|c|c|c|c|c|c|}
\hline & No. & SPINK1* 14/2 & $21(6.3 \%)$ & $O R *(95 \% C l)$ & $P$ value & CFTR $^{* *}$ 5/221 (2.3 \%) & OR $(95 \%$ Cl) & $P$ value & CTRC $^{* *} 4 / 221$ (1.8\%) & OR $(95 \%$ Cl) & $P$ value \\
\hline \multicolumn{12}{|c|}{ Severity of the course } \\
\hline Mild AP & 144 & $6(4.2 \%)$ & & $2.05(0.85-5.1)$ & $P<0.005$ & $4(2.8 \%)$ & $0.59(0.16-1.80)$ & NS & $2(1.4 \%)$ & $1.57(0.29-8.52)$ & NS \\
\hline Moderate AP & 39 & 7 (17.9\%) & $8(10.4 \%)$ & & & 0 & & & $2(1.4 \%)$ & & \\
\hline Severe AP & 38 & $1(2.6 \%)$ & & & & $1(2.6 \%)$ & & & $1(2.6 \%)$ & & \\
\hline \multicolumn{12}{|l|}{ Etiology of AP } \\
\hline Alcohol & 70 & $5(7.1 \%)$ & & $2.33(0.61-7.57)$ & NS & $1(1.4 \%)$ & $0.37(0.01-2.55)$ & NS & $2(2.9 \%)$ & $2.50(0.22-17.84)$ & NS \\
\hline Gallstones & 81 & 5 (6.2 \%) & & $1.99(0.53-6.45)$ & & $3(3.7 \%)$ & $0.98(0.18-3.7)$ & & $2(2.5 \%)$ & $2.15(0.19-15.33)$ & \\
\hline Idiopathic & 63 & $4(6.3)$ & & $2.05(0.46-7.23)$ & & 0 & $0(0-1.78)$ & & 0 & $0(0-8.365)$ & \\
\hline Cancer & 7 & 0 & & $0(0-23.88)$ & & $1(14.3 \%)$ & $4.2(20.09-39.08)$ & & 0 & $0(0-85.65)$ & \\
\hline \multicolumn{12}{|c|}{ Reccurrences of AP } \\
\hline Yes & 82 & $5(6.1 \%)$ & & $1.97(0.52-6.37)$ & NS & $1(1.2 \%)$ & $0.32(0.01-2.16)$ & NS & $2(2.4 \%)$ & $2.13(0.19-15.135)$ & NS \\
\hline No & 139 & $9(6.5 \%)$ & & $2.10(0.75-5.72)$ & & $4(2.9 \%)$ & $0.76(0.18-2.51)$ & & $2(1.4 \%)$ & $1.24(0.111-8.8$ & \\
\hline Control group & 345 & $11(3.2 \%)^{*}$ & & & & $13(3.8 \%)^{* *}$ & & & $4(1.2 \%)^{* *}$ & & \\
\hline
\end{tabular}

Indicates that the odds of SPINK1 mutations are 2.05 times higher in the AP group than in the control group. The limits $(0.847 ; 5.096)$ for OR $95 \%$ confidence interval are not very wide, so the OR estimate has rather good precision. The association between the group and the SPINK1mutations occurrence is not significant at the 0.05 level because $95 \%$ confidence interval for the OR contains 1 . However, right-sided F exact test rejects the null hypothesis that $\mathrm{OR}=1$ in favour of the alternative hypothesis that true odds ratio is higher than $1(p=0.0466)$. This means that the odds of SPINK1 in the AP group are higher than in the control group, rejects the nul hypothis that as no staistical significance

*SPINK1 mutation in the ace

preatitis group (AP) is more frequent than in the control group: $p<0.005$

**The differences between the CFTR, CTRC mutations in the acute pancreatitis group (AP) and in the control group are insignificant 
site in the protein serves as a specific target substrate for trypsin. SPINK1 polymorphisms are common in the general population $(\sim 2 \%)$ and are significantly associated with pancreatitis [12]. The results of studies of p.N34S SPINK1 mutation in acute pancreatitis are divergent. Tukiainen et al. [13] evaluated the frequency of mutation in SPINK1 in 371 patients with acute pancreatitis, including 207 with the mild form and 164 with the severe form. The control group comprised 459 individuals. The p.N34S mutation occurred in 29 patients (7.8 \%) and 12 individuals $(2.6 \%)$ in the control group. In the majority of patients, the disease had an alcohol-related etiology $(n=229 ; 61 \%)$. The frequency of p.N34S mutation was higher in the group with severe disease (15/164; $9.1 \%)$ and with alcoholic etiology $(21 / 229 ; 9.2 \%)$. The differences were not statistically significant. No differences between age and number of attacks were observed in the groups examined. The researchers concluded that the p.N34S mutation in SPINK1 may increase susceptibility to acute pancreatitis. O'Reilly et al. [14] confirmed the relationship between this mutation and AP. The abovementioned mutation occurred significantly more often in patients with AP. The authors suggest that this mutation predisposes to premature protease activation in the development of pancreatitis. In turn, Aounet al. [15] found that p.N34S mutation in SPINK1 was not associated with the first attack of pancreatitis; however, it increased the risk of recurrence. In the present study, the frequency of SPINK1 mutations in 221 patients with pancreatitis was $6.3 \%$, which was significantly higher than in the control group $(P=0.03)$. This mutation also occurred significantly more frequently in the patients with moderate and severe forms of AP $(P=0.03)$, compared with those with a mild course of the disease. Our study confirmed the importance of this mutation as a predisposing factor for AP, and was simultaneously responsible for the more severe course of the disease. No differences were observed in the frequency of mutations in individual subgroups according to the cause (alcoholic, biliary, idiopathic, and others). Thus, our observations and those of other researchers suggest that SPINK1 mutations predispose to severe pancreatitis. Such a relationship was not found in studies of Polish patients with CP. However, it should be stated that the group examined was several times smaller than that investigated in the present study [16].

The studies conducted to date suggest that the spectrum of mutations in SPINK1 is geographically varied: the IVS $3+2 \mathrm{~T}>\mathrm{C}$ mutation is more frequent in Chinese children with Idiopathic chronic pancreatitis (ICP), whereas p.N34S is more frequent among western populations. The role of IVS3 $+2 \mathrm{~T}>\mathrm{C}$ mutation has not been finally recognized. It may exert an effect on gene transcription; or it may be the cause of translocation of the entire exon 3 where there is a binding site for trypsin, damaging the splicing donor site, and in the final phase, causing disorder in the protease/antiprotease balance in the pancreas. Further studies are necessary to explain the molecular mechanisms [17].

In the present study, the p.N34S mutation in SPINK1 was most frequently observed (5.4\% in patients with AP and $0.3 \%$ in the control group), and more rarely, p.P55S mutation $(0.9 \%$ and $0.6 \%$ in the control group). The IVS3 + 2 T > C mutation in SPINK1 often occurred in the study by Wanga et al. [11] $-57.3 \%$ of cases; however, they did not find any p.N34S mutation in SPINK1. Kume et al. [18] observed these mutations in 13-17 \% of Japanese patients. The IVS3 $+2 \mathrm{~T}>\mathrm{C}$ mutation in SPINK1 was often noted in Korean patients with idiopathic and familial pancreatitis [19]. Studies conducted in western countries indicated that this mutation occurred in only 1 ( $1 \%)$ of 96 patients, and in $3(2.7 \%)$ of 112 pediatric patients with ICP [20]. Pfutzer et al. [21] showed that N34S mutation in SPINK1 was seen in $40 \%$ $(23 / 57)$ of American children with ICP, while Truninger et al. [10] found it in $43 \%(6 / 14)$ of German patients with early onset of ICP.

Wang et al. [11] observed that the frequency of mutation in SPINK1 (57.3\%) was higher than that described by Witt et al. (19-40\%). Mystakidis et al. [22] did not find any mutation in SPINK1 in a group of 30 patients with pancreatitis after ERCP, and concluded that this mutation does not play any important role in the pathogenesis of this type of pancreatitis. Nevertheless, we consider that more comprehensive studies should be carried out to confirm these results. In our study, no patients developed post-ERCP pancreatitis.

Recent studies have suggested an important role for CFTR in the development of pancreatitis, particularly through its role in intraluminal $\mathrm{pH}$ regulation from bicarbonate secretion and the flushing of ductal proteins. Secretory granules of pancreatic acinar cells co-release protons with digestive enzymes during normal pancreatic secretion. Diminished ductal bicarbonate secretion and consequent reduced alkalinization of the acinar lumen may promote the development of pancreatitis since acidification of the pancreatic lumen can lead to a loss of tight junction integrity, allowing the leakage of digestive enzymes into the pancreatic duct lumen and interstitial space [23]. Stressors, such as oxidative damage, overloading the protein-folding capacity of the endoplasmic reticulum, trigger the unfolded protein response [24].

Obstructive tubulopathy of the pancreas is the result of CFTR dysfunction and plays a primary role in the development of $\mathrm{CP}$; however, the precise process of the course of the inflammation has not been fully established. The function of CFTR in the pancreas is important for the 
dilution and alkalinization of protein-rich secretions, and therefore, plays a preventive role in the formation of protein plugs in the pancreatic ducts. Partial loss of CFTR function may be related to idiopathic and alcohol-related pancreatitis. Recently, Schneider et al. [25] have described that the co-occurrence of R75Q mutation in CFTR and variants of SPINK1 was considerably higher in patients with ICP, compared with the control group $(8.75 \%$ vs. $0.38 \%)$. Using the patchclamp technique, they found that CFTR may be the cause of disturbed secretion of bicarbonates and increased risk of pancreatitis. A large number of CFTR mutations and the presence of specific CFTR genotype are associated with pancreatitis. In the present study, there was no significant difference in the proportions of mutations in CFTR in the AP group (5/221; $2.3 \%)$ and control group $(13 / 345 ; 3.8 \%)$. The observed proportions were: 0.023 and 0.038 , respectively. The $\mathrm{Z}$ score was -0.9959 and the $P$ value was 0.15866 . No relationship was confirmed in mutations with severe AP: mild AP mutation of CFTR in $4(2.8 \%)$ patients, and in the SAP mutation of CFTR in 1 (2.6\%) patient. Rosendahl et al. [26] examined 660 patients with chronic pancreatitis and noted that the accumulation of CFTR variants in chronic pancreatitis was lower than described previously; nevertheless, the presence of these variants may have increased the risk of development of the disease by $2.7-4.5$ fold. The studies confirmed a complex genetic interaction with $\mathrm{CP}$, and a smaller effect of CFTR variants in the development of the disease.

The mechanisms by which $C T R C$ protects against pancreatitis have been established; however, the importance of CTRC variants in terms of risk for RAP and CP is less clear [27]. The CTRC mutations may predispose to CP through ineffective trypsin degradation, ineffective carboxypeptidase activation, and induction of endoplasmic reticulum [27]. The CTRC mutation is related with chronic pancreatitis in European and Asian populations. Wang et al. [11] did not find mutations in Chinese children with idiopathic pancreatitis, and indicated that CTRC mutation may vary geographically and ethnically. In our own studies, CTRC mutation occurred with a similar frequency in the study group with AP (4/221; $1.8 \%)$ and in the control group (4/345; $1.2 \%)$. No differences were observed between individual subgroups of AP severity. No p.A73T mutations in CTRC were found in the patient or control group. The p.K247_R254del mutation in CTRC was confirmed in 1 patient with AP and 3 healthy individuals. The remaining mutations examined, p.E225A, p.V235I and p.I259V in CTRC, occurred singly in the group of patients with $\mathrm{AP}$ and in the healthy volunteers.

Chang et al. [28] evaluated a Chinese cohort of cases of $\mathrm{CP}$ and associated additional mutations with $\mathrm{CP}$, but did not replicate the previous findings. Rosendahl et al.
[26] showed that the rare p.R254W and p.K247_R254del variants were significantly over-represented in cases of pancreatitis in Germany.

\section{Conclusions}

The N34S mutation of SPINK1 may predispose to AP, especially in patients who abuse alcohol, and may result in a more severe course of the disease. The accumulation of various mutations and environmental factors may be of importance in the development of AP.

\begin{abstract}
Abbreviations
AP: Acute pancreatitis; CP: Chronic pancreatitis; PRSS1: Cationic trypsinogen gene; PRSS2: Anionic tripsinogen; SPINK1: The pancreatic secretory trypsin inhibitor gene; CFTR: The cystic fibrosis transmembrane conductance regulator gene; CTRC: The chymotrypsinogen gene; CASR: The calcium-sensing receptor gene; CLDN2: The protein claudin-2; SAP: Severe acute pancreatitis; CT: Images computed tomography; NMR: Nuclear magnetic resonance; USG: Ultrasonography; ERCP: Endoscopic retrograde cholangiopancreatography; HRM: High resolution melting; ASA-PCR: Allele-specific PCR; ICP: Idiopathic chronic pancreatitis..
\end{abstract}

\section{Competing interests}

The authors declare that they have no competing interests. We guarantee that this paper is original and has not been published in any form to date, nor is it under consideration by any other editorial boards.

\section{Authors' contributions}

DK and SG were responsible for the project conception, patients' recruitment, and collection of clinical data. DK, SG and AK designed the study, interpreted genetic and clinical data, and wrote the manuscript. AK designed the genetic analysis, assisted by $M C H$ and LP. MCH and LP conducted the genetic studies, which were analyzed and interpreted by AK, MCH and LP. All authors read and approved the final manuscript.

\section{Author details}

${ }^{1}$ Faculty of Health Sciences, Jan Kochanowski University, Kielce, Poland. ${ }^{2}$ Clinic General Oncological and Endocrinological Surgery, Regional Hospital, Kielce, Poland. ${ }^{3}$ Department of Molecular Diagnostics, Holy Cross Cancer Centre, Kielce, Poland.

Received: 11 October 2014 Accepted: 16 June 2015

Published online: 23 June 2015

\section{References}

1. Kozieł D, Kozłowska M, Deneka J, Matykiewicz J, Głuszek S. Retrospective analysis of clinical problems concerning acute pancreatitis in one treatment center. Prz Gastroenterol. 2013;8:320-6.

2. Yadaw D, Eigenbrodt ML, Briggs MJ, Williams DK, Wiseman EJ. Pancreatitis: prevalence and risk factors among male veterans in a detoxification program. Pancreas. 2007;34:390-8.

3. Whitcomb DC. Genetic risk factors for pancreatic disorders. Gastroenterology. 2013;144:1292-302.

4. Keller J, Layer P. Idiopathic chronic pancreatitis. Best Pract Res Clin Gastroenterol. 2008;22:105-13.

5. Gluszek S, Koziel D. Prevalence and progression of acute pancreatitis in the świętokrzyskie voivodeship population. Pol Przegl Chir. 2012;84:618-25.

6. Solomon S, Whitcomb DC. Genetics of pancreatitis: an update for clinicians and genetic counselors. Curr Gastroenterol Rep. 2012;14:112-7.

7. Chandak GR, Idris MM, Reddy DN, Mani KR, Bhaskar S, Rao GV, et al. Absence of PRSS1 mutations and association of SPINK1 trypsin inhibitor mutations in hereditary and non-hereditary chronic pancreatitis. Gut. 2004:53:723-8.

8. Koziel D, Kowalik A, Piecak L, Chlopek M, Gluszek S. The frequency of SPINK 1, PRSS1 and CFTR mutations in acute pancreatitis [abstract]. Pancreatology. 2013;13(3S):S55

9. Koziel D, Gluszek S, Kowalik A, Chlopek M. Genetic factors in acute pancreatitis [abstract]. Pancreatology. 2014;14(3S):96. 
10. Truninger K, Kock J, Wirth HP, Muellhaupt B, Arnold C, von Weizsäcker F, Seifert B, Ammann RW, Blum HE. Muellhaupt B. Trypsinogen gene mutations in patients with chronic or recurrent acute pancreatitis. Pancreas. 2001:22:18-23.

11. Wang W, Sun XT, Weng XL, Zhou DZ, Sun C, Xia T, Hu LH, Lai XW, Ye B, Liu MY, Jiang F, Gao J, Bo LM, Liu Y, Liao Z, Li ZS. Comprehensive screening for PRSS1, SPINK1, CFTR, CTRC and CLDN2 gene mutations in Chinese paediatric patients with idiopathic chronic pancreatitis: a cohort study. BMJ. 2013;3, e003150.

12. Ravi Kanth V, Nageshwar RD. Genetics of acute and chronic pancreatitis: an update. World J Gastrointest Pathophysiol. 2014;5:427-37.

13. Ooi CY1, Durie PR. Cystic fibrosis transmembrane conductance regulator (CFTR) gene mutations in pancreatitis. J Cyst Fibros. 2012;11:355-62.

14. Lugea A, Tischler D, Nguyen J, Gong J, Gukovsky I, French SW, Gorelick FS, Pandol SJ. Adaptive unfolded protein response attenuates alcohol-induced pancreatic damage. Gastroenterology. 2011;140:987-97.

15. Aoun E, Muddana V, Papachristou GI, Whitcomb DC. SPINK1 N34S is strongly associated with recurrent acute pancreatitis but is not a risk factor for the first or sentinel acute pancreatitis event. Am J Gastroenterol. 2010;105:446-51.

16. Gasiorowska A, Talar-Wojnarowska R, Czupryniak L, Smolarz B, RomanowiczMakowska H, Kulig A, Malecka-Panas E. The prevalence of cationic trypsinogen (PRSS1) and serine protease inhibitor, Kazal type 1 (SPINK1) gene mutations in Polish patients with alcoholic and idiopathic chronic pancreatitis. Dig Dis Sci. 2011:56:894-901

17. Witt H, Luck W, Becker M. A signal peptide cleavage site mutation in the cationic trypsinogen gene is strongly associated with chronic pancreatitis. Gastroenterology. 1999:117:7-10.

18. Kume K, Masamune A, Kikuta K, Shimosegawa T. [-215G > A; IVS3 + 2 T > C] mutation in the SPINK1 gene causes exon 3 skipping and loss of the trypsin binding site. Gut. 2006;55:1214.

19. Oh HC, Kim MH, Choi KS, Moon SH, Park Do H, Lee SS, Seo DW, Lee SK, Yoo HW, Kim GH. Analysis of PRSS1 and SPINK1 mutations in Korean patients with idiopathic and familial pancreatitis. Pancreas. 2009;38:180-3.

20. Witt H1, Luck W, Hennies HC, Classen M, Kage A, Lass U, Landt O, Becker M: Mutations in the gene encoding the serine protease inhibitor, Kazal type 1 are associated with chronic pancreatitis. Nat Genet. 2000, 25:213-6.

21. Pfützer RH1, Barmada MM, Brunskill AP, Finch R, Hart PS, Neoptolemos J, Furey WF, Whitcomb DC: SPINK1/PSTI polymorphisms act as disease modifiers in familial and idiopathic chronic pancreatitis. Gastroenterology 2000, 119:615-23.

22. Mystakidis K, Kouklakis G, Papoutsi A, Souftas VD, Efremidou E, Kapetanos D, Pitiakoudis M, Lyratzopoulos N, Karagiannakis A, Pantelios A. Is post-ERCP pancreatitis a genetically predisposed complication? Gastroenterol Res Pract. 2012;2012:473960

23. Tukiainen $E$, Kylänpää ML, Kemppainen E, Nevanlinna $H$, Paju A, Repo $H$, Stenman UH, Puolakkainen P. Pancreatic secretory trypsin inhibitor (SPINK1) gene mutations in patients with acute pancreatitis. Pancreas. 2005;30:239-42.

24. O'Reilly DA, Witt H, Rahman SH, Schulz HU, Sargen K, Kage A, Cartmell MT, Landt O, Larvin M, Demaine AG, McMahon MJ, Becker M, Kingsnorth AN. The SPINK1 N34S variant is associated with acute pancreatitis. Eur J Gastroenterol Hepatol. 2008;20:726-31.

25. Schneider A1, Larusch J, Sun X, Aloe A, Lamb J, Hawes R, Cotton P, Brand RE, Anderson MA, Money ME, Banks PA, Lewis MD, Baillie J, Sherman S, Disario J, Burton FR, Gardner TB, Amann ST, Gelrud A, George R, Rockacy MJ, Kassabian S, Martinson J, Slivka A, Yadav D, Oruc N, Barmada MM, Frizzell R, Whitcomb DC: Combined bicarbonate conductance-impairing variants in CFTR and SPINK1 variants are associated with chronic pancreatitis in patients without cystic fibrosis. Gastroenterology 2011, 140:162-71.

26. Rosendahl J, Landt O, Bernadova J, Kovacs P, Teich N, Bödeker H, Keim V, Ruffert C, Mössner J, Kage A, Stumvoll M, Groneberg D, Krüger R, Luck W, Treiber M, Becker M. CFTR, SPINK1, CTRC and PRSS1 variants in chronic pancreatitis: is the role of mutated CFTR overestimated? Gut. 2013;62(4):582-92

27. Zhou J, Sahin-Tóth M. Chymotrypsin C mutations in chronic pancreatitis. J Gastroenterol Hepatol. 2011;26:1238-46.

28. Chang YT, Wei SC, PC L, Tien YW, Jan IS, Su YN, Wong JM, Chang MC. Association and differential role of PRSS1 and SPINK1 mutation in early-onset and late-onset idiopathic chronic pancreatitis in Chinese subjects. Gut. 2009;58:885.

\section{Submit your next manuscript to BioMed Central and take full advantage of:}

- Convenient online submission

- Thorough peer review

- No space constraints or color figure charges

- Immediate publication on acceptance

- Inclusion in PubMed, CAS, Scopus and Google Scholar

- Research which is freely available for redistribution

Submit your manuscript at www.biomedcentral.com/submit 